\title{
Clinical characteristics and in-hospital outcome of medical staff infected with COVID-19 in Saudi Arabia
}

\author{
A retrospective single-center study
}

Samah I. Abohamr, MD, FASE, Mubarak A. Aldossari, MD, PhD, Faisal A. Alaklobi, MD, Hala A. Amer, MD, PhD, Shaimaa H. Alzarzour, Bs, MPH, Sara W. Abdelhamid, HSDG, ObaidAljunaidi, MD, Omar S. Badhawi, MD, Shireen Siddiqui, MD, Hanem Jumaa, RN, CIC, Muhammad Badwi, RN, MPH, Eman Elsheikh, MD, PhD.

\begin{abstract}
الأهداف : تحليل الخصائص السريرية والنتائج داخل المستشفى بين أفراد الطاقم الطبي

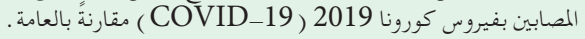

المنهجية: اشتملت الدراسة على 108 من من مرضى الطاقم الطبي المصابين بفيروس

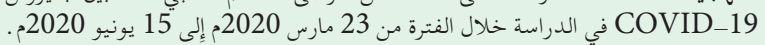

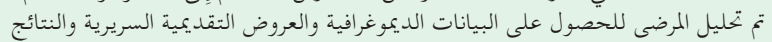

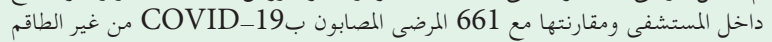
الطبي.

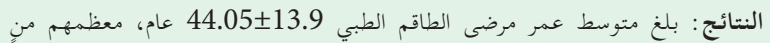

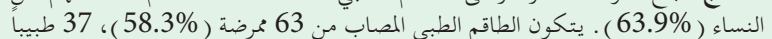

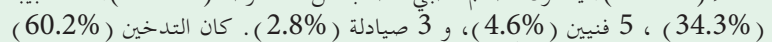

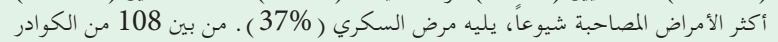

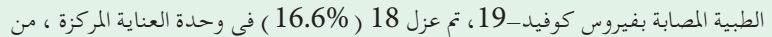

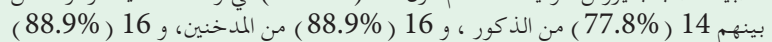





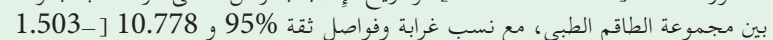
[77.287

الحخلاصة : كان معدل الإصابة بعدوى COVID_19 بين الطاقم الطبي مرتفعًا للغاية،

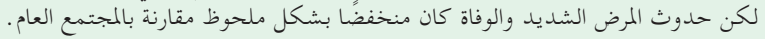

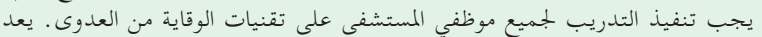

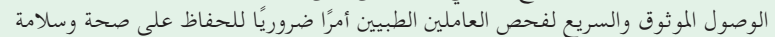

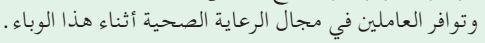

Objectives: To analyze the clinical characteristics and in-hospital outcomes among coronavirus disease 2019 (COVID-19) positive medical staff compared with those of public.

Methods: A total of 108 COVID-19-positive medical staff patients were included in the study from March 23, 2020 to June 15, 2020. Patients were analyzed for demographic data, clinical presentations, and in-hospital outcomes and compared against 661 COVID-19infected patients of non-medical personnel.

Results: Mean age of medical staff patients was $44.05 \pm 13.9$ years, most of whom were women (63.9\%). The infected medical staff members consisted of 63 nurses (58.3\%), 37 physicians (34.3\%), 5 technicians (4.6\%), and 3 pharmacists $(2.8 \%)$. Smoking $(60.2 \%)$ was the most frequent, followed by diabetes mellitus (37\%). Of 108 COVID-19 infected medical staff, 18 (16.6\%) were isolated in the intensive care unit (ICU), of which 14 $(77.8 \%)$ were male, $16(88.9 \%)$ were smokers, and 16 $(88.9 \%)$ presented with pneumonia. Fatality ratio among medical staff patients was $4.6 \%$. Male gender with odds ratios (OR) of 7.771 and $95 \%$ confidence intervals (CI) of 0.837-72.195 and a history of chronic kidney disease of (OR=10.778, 95\% CI: 1.503-77.287) were predictors of death among the medical staff group.

Conclusion: The incidence of COVID-19 infection among medical staff is quite high, but the occurrence of extreme illness and death is significantly low compared with the general community. Training should be implemented for all hospital staff on infection prevention techniques. Reliable and quick access for testing medical personnel is essential to maintain health, safety, and availability of health care workers during this pandemic.

Keywords: medical staff, COVID-19, in-hospital outcome, Saudi Arabia

\section{Saudi Med J 2020; Vol. 41 (12): 1336-1343} doi: 10.15537/smj.2020.12.25514

From the Department of Cardiology (Abohamr, Elsheikh), Tanta University Hospital, from the Department of Community Medicine (Amer), National Research Center, Eygpt; from the Heart Health Center (Abohamr, Aldossari, Aljunaidi, Badhawi); from the Department of Infectious Diseases Pediatric and Infection Control (Alaklobi); from the Department of Prevention and Control of Infection (Amer, Alzarzour, Jumaa, Badwi); from the Department of Microbiology (Siddiqui), King Saud Medical City, from the College of Medicine (Abdelhamid), Alfaisal University, Riyadh; and from the Internal Medicine Department (Elsheikh), King Faisal University, Alahsa, Kingdom of Saudi Arabia.

Received 18th September 2020. Accepted 20th October 2020

Address correspondence and reprint request to: Dr. Eman Elsheikh, Internal Medicine Department, College of Medicine, King Faisal University, Alahsa, Kingdom of Saudi Arabia. E-mail: emancardiology@yahoo.com

ORCID ID: https://orcid.org/0000-0002-3150-7125 
$\mathrm{C}$ oronavirus disease-2019 (COVID-19) has been declared by the World Health Organization (WHO) to be an international public health emergency. ${ }^{1}$ The pathogen was identified as a new ribonucleic acid envelope, betacoronavirus-2, named severe acute respiratory syndrome coronavirus 2 (SARS-CoV-2) and is phylogenetically similar to SARS-CoV. ${ }^{2}$

The ongoing COVID-19 pandemic affected Kingdom of Saudi Arabia (KSA) early and hard. The Ministry of Health declared the appearance of the first case in KSA on March, 2020. ${ }^{3}$ By August 2020, the total number of confirmed cases has reached 310,836 , with 3,755 fatalities. ${ }^{3,4}$

Coronavirus disease-2019 often presents initially with non-specific symptoms, including fever, dry cough, and fatigue. The infection can affect various systems, including the respiratory, gastrointestinal, musculoskeletal, and neurological systems. The disease can progress quickly to acute respiratory distress syndrome (ARDS). ${ }^{5}$ Older patients, patients with chronic medical conditions, such as heart, lung, kidney, and liver diseases, and immunosuppressed patients, including diabetic and cancer patients, have higher risks of mortality associated with organ failure within a short period. ${ }^{6}$

Globally, although millions of people have remained at home to prevent the transmission of SARS-CoV-2, healthcare professionals have engaged in the exact opposite behavior; they regularly work in hospitals and clinics and are at high risk of COVID-19 infection. ${ }^{7}$ In the United States, health care professionals accounted for $11 \%$ of reported COVID-19 cases. $^{8}$ In a recent study, 40 of 138 (29\%) patients admitted to a hospital in Wuhan, China were medical professionals. ${ }^{9}$ Moreover, among 1,099 confirmed COVID-19 patients at 552 hospitals, across 31 Chinese provinces, healthcare staff comprised $3.5 \%$ of cases. ${ }^{10}$

Coronavirus disease-2019 has placed extraordinary demands upon healthcare providers who are potentially the most crucial tools necessary for every country to battle this disease. ${ }^{11,12}$ This single-center, retrospective study aimed to describe the demographic data, clinical presentations, and outcomes of verified COVID-19 patients among the medical staff (MS) at King Saud Medical City (KSMC), Riyadh, KSA.

Disclosure. Authors have no conflict of interests, and the work was not supported or funded by any drug company.
Methods. A descriptive, cross-sectional, singlecenter, retrospective study was performed, which included adult, COVID-19 patients at KSMC, between March 23, 2020 and June 15, 2020. Inclusion criteria was confirmed COVID-19 positive patients with complete medical records. Patients with incomplete or unavailable medical files are excluded. Demographic data, clinical status information (including symptoms and signs), comorbid conditions, and outcome data were obtained from electronic medical files.

Enrolled patients were classified into 2 groups. One group composed of MS personnel, including physicians, nurses, technicians, and pharmacists. The other group included positive COVID-19 patients who were not MS.

The COVID-19 suspicion-to-confirmation process is guided by the guidelines established by the Saudi Centers for Disease Control and Prevention (CDC), which were written and updated recently, in June 2020, based on the best currently available data and evidence. ${ }^{13}$ Confirmation of COVID-19 infection was based on a positive polymerase chain reaction (PCR) test of nasopharyngeal swab. The clinical outcomes categorized into home-isolation, hospitalization, and death. The hospital admission of all suspected cases was mandatory during the early stages of this pandemic, in KSA, and confirmed cases were referred to designated facilities for further follow-ups. As the situation progresses, the home isolation of suspected and confirmed, clinically stable cases with COVID-19 has been permitted, if criteria specified by the Saudi Ministry of Health have been met. ${ }^{14}$ This work has been carried out in compliance with the ethical approval of the KSMC Ethics Committee and the Declaration of Helsinki and its amendments by the World Medical Association (WMA).

Statistical analysis. The data analysis was carried out using Microsoft Excel 2016 and the Statistical Package for Social Sciences, version 26 (IBM Corp., Armonk, NY, USA). Continuous, normally distributed variables are represented as the mean and standard deviation (SD) with a 95\% confidence interval (CI), whereas frequencies and percentages are used for categorical variables. A $p$-value $<0.05$ was considered significant. The tudent's t-test was conducted to compare the means of variables normally distributed between groups and the $\chi^{2}$ test or Fisher's exact test was used to compare the distribution between groups of categorical variables. Effect modifications were evaluated by stratification, and statistical interactions were assessed by including main predictor variables and their product terms in 
a binary logistic regression analysis, in addition to performing a multinomial logistic regression analysis.

Results. During the period of the study, 2,048 patients were diagnosed with COVID-19, including 483 MS members. Among patients with available data, 108 were MS and 661 patients were non-MS, (Figure 1). The mean age of the MS group was $44.05 \pm 13.9$ years, whereas the mean age of the non-MS group was $46.4 \pm 14.25$ years. Women comprised the majority $63.9 \%$ of the MS group, while men constitute $36.1 \%$ $(p=0.001)$. On the other side, men comprised the majority of the non-MS group $76.9 \%$ whereas women were $23.1 \% \quad(p=0.001)$. Individuals of non-Saudi nationality comprised most of both groups. The details regarding the demographic data are shown in Table 1.

Nurses constituted $58 \%$ of the MS group, physicians represented $34 \%$, technicians in the laboratory and intensive care unit (ICU) comprised 5\%, and 3\% were pharmacists.

Among known comorbidities, smoking was the most frequently identified comorbidity among the MS group, which occurred at a significantly higher rate than that among the non-MS group $(60.2 \%$ vs $21.6 \%$, $p=0.001$ ), whereas diabetes was the most prevalent comorbidity among the non-MS group, although the difference did not quite meet the significance threshold compared with the MS group ( $47 \%$ vs $37.0 \%, p=0.05$ ). Hypertension and a history of lung disease were significantly more prevalent among the non-MS group (36.2\% vs $17.6 \%, p=0.001)$ compared with the MS group $(14.5 \%$ vs $7.4 \%, p=0.04)$. The distributions of other comorbidities are illustrated in Table 1.

Clinical presentation. Most patients presented with common symptoms of COVID-19 infection, which were distributed similarly among both groups. Almost all patients in both groups reported at least one of the following symptoms: fever, $88.9 \%$ of MS and $83.8 \%$ of non-MS; cough, $88 \%$ of MS and $81.4 \%$ of non-MS; shortness of breath, $85.2 \%$ of MS and $79.1 \%$ of non-MS; and pneumonia, $65.7 \%$ of MS and $71 \%$ of non-MS. All other clinical presentations are listed for both groups in Table 1 .

Management plan and complications. Respiratory complications occurred more frequently in the MS group compared with the other group. Acute respiratory distress syndrome (ARDS) was notably more prevalent among the MS group than the non-MS group (14.8\%

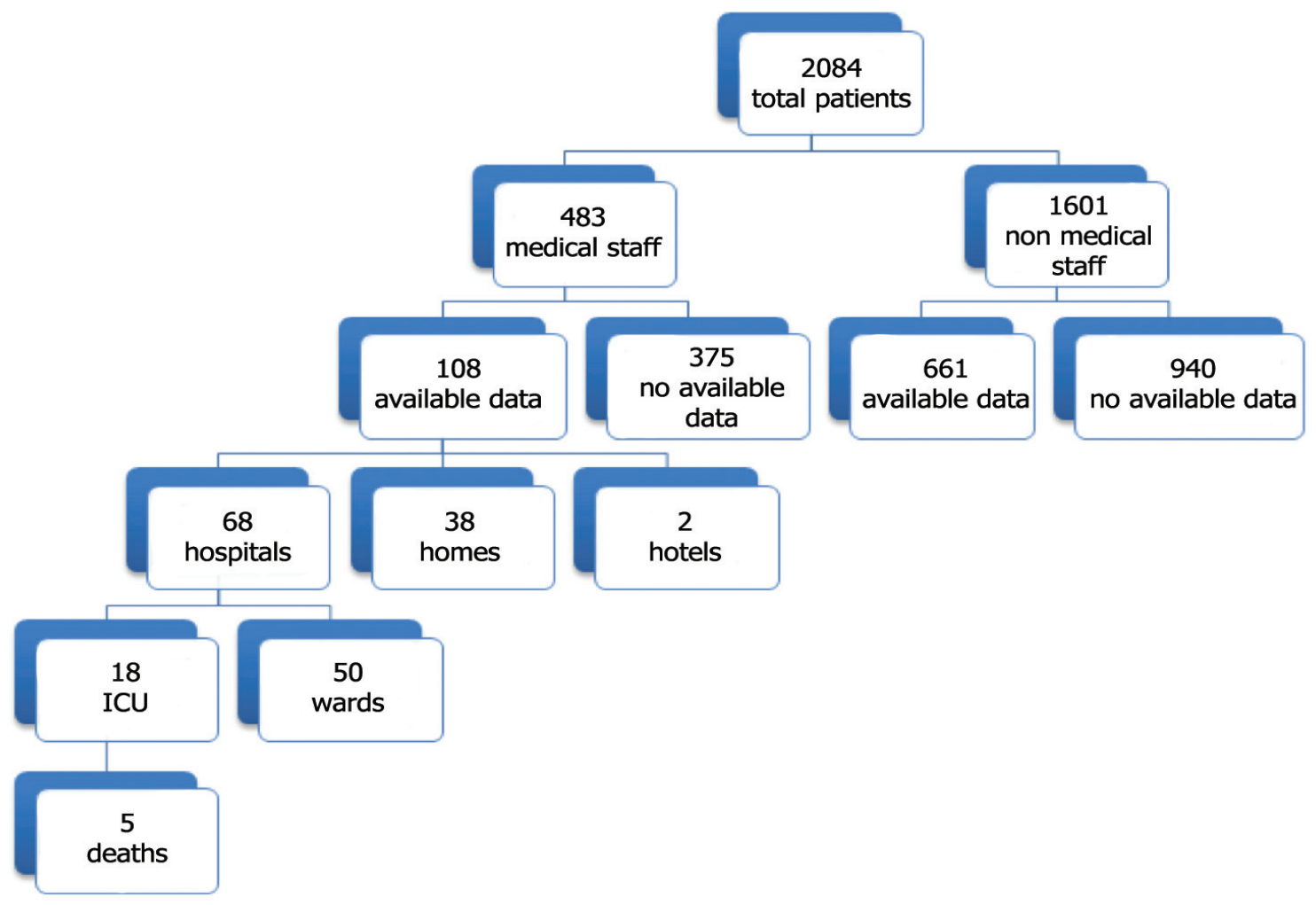

Figure 1 - The flowchart of analysis procedure. ICU: intensive care unit 
Table 1 - Demographics and clinical characteristics of all studied groups $(\mathrm{N}=769)$.

\begin{tabular}{|c|c|c|c|}
\hline Demographic data & $\begin{array}{c}\text { Medical staff } \\
(\mathrm{n}=108)\end{array}$ & $\begin{array}{l}\text { Non-medical } \\
\text { staff }(n=661)\end{array}$ & $P$-value \\
\hline Age (years) Mean $\pm S D$ & $44.05 \pm 13.9$ & $46.4 \pm 14.2$ & 0.1 \\
\hline \multicolumn{4}{|l|}{ Occupation } \\
\hline Technician & $5(4.6)$ & \multirow{4}{*}{$661(100)$} & \\
\hline Nurse & $63(58.3)$ & & \\
\hline Pharmacist & $3(2.8)$ & & \\
\hline Physician & $37(34.3)$ & & \\
\hline \multicolumn{4}{|l|}{ Gender } \\
\hline Female & $69(63.9)$ & $153(23.1)$ & \\
\hline Male & $39(36.1)$ & $508(76.9)$ & $0.001^{\dagger}$ \\
\hline \multicolumn{4}{|l|}{ Nationality } \\
\hline Saudi & $152(23.0)$ & $26(24.1)$ & \multirow{2}{*}{0.7} \\
\hline Non-Saudi & $509(77.0)$ & $82(75.9)$ & \\
\hline \multicolumn{4}{|l|}{ History of comorbidities } \\
\hline Smoker & $65(60.2)$ & $143(21.6)$ & $0.001^{\dagger}$ \\
\hline Obesity & $24(22.2)$ & $120(18.2)$ & 0.3 \\
\hline Hypertension & $19(17.6)$ & $239(36.2)$ & $0.001^{\dagger}$ \\
\hline $\mathrm{CKD}$ & $8 \quad(7.4)$ & $88(13.3)$ & 0.08 \\
\hline Diabetes mellitus & $40(37.0)$ & $311(47.0)$ & 0.05 \\
\hline CVA & $3(2.8)$ & $40 \quad(6.1)$ & 0.2 \\
\hline CVD & $9(8.3)$ & $72(10.9)$ & 0.4 \\
\hline Lung disease & $8 \quad(7.4)$ & $96(14.5)$ & $0.04^{*}$ \\
\hline \multicolumn{4}{|l|}{ Clinical presentation } \\
\hline Fever & $96(88.9)$ & $554(83.8)$ & 0.2 \\
\hline Cough & $95(88.0)$ & $538(81.4)$ & 0.09 \\
\hline Shortness of breath & $92(85.2)$ & $523(79.1)$ & 0.2 \\
\hline Pneumonia & $71(65.7)$ & $469(71.0)$ & 0.3 \\
\hline Heart failure & $3(2.8)$ & $29(4.4)$ & 0.4 \\
\hline $\begin{array}{l}\text { Acute coronary } \\
\text { syndrome }\end{array}$ & $0 \quad(0.0)$ & $39 \quad(5.9)$ & $0.01^{*}$ \\
\hline Arrhythmia & $0 \quad(0.0)$ & $8 \quad(1.2)$ & 0.2 \\
\hline \multicolumn{4}{|l|}{ Complications } \\
\hline ARDS & $16(14.8)$ & $45(6.8)$ & $0.004^{\dagger}$ \\
\hline Septic shock & $3(2.8)$ & $135(20.4)$ & $0.001^{\dagger}$ \\
\hline Respiratory failure & $13(12.0)$ & $38 \quad(5.7)$ & $0.02^{*}$ \\
\hline Acute kidney injury & $4 \quad(3.7)$ & $130(19.7)$ & $0.001^{\dagger}$ \\
\hline Death & $5(4.6)$ & $89(13.5)$ & $0.01^{*}$ \\
\hline \multicolumn{4}{|c|}{ Isolation status after confirmation } \\
\hline Home isolation & $38(35.2)$ & $199(30.1)$ & \\
\hline Hotel isolation & $2(1.9)$ & $7(1.1)$ & 0.4 \\
\hline Hospital isolation & $68(63.0)$ & $455(68.8)$ & \\
\hline Ward isolation & $50(73.5)$ & $221(48.6)$ & $0.01^{*}$ \\
\hline ICU isolation & $18(26.5)$ & $234(51.4)$ & $0.01^{*}$ \\
\hline
\end{tabular}

Values are presented as number and percentages (\%). CKD: chronic kidney disease, CVA: cerebrovascular accident, CVD: cardiovascular disease, ARDS: acute respiratory distress syndrome, ICU: intensive care unit. ${ }^{*} p<0.05$ is significant, ${ }^{\dagger} p<0.01$ is highly significant vs $6.8 \%, p=0.004)$. Respiratory failure $(\mathrm{RF})$ was also significantly more common among MS patients than non-MS patients ( $12 \%$ vs $5.7 \%, p=0.02)$, (Table 1 ).

Of 108 total patients in the MS group, 63\% were hospitalized, either in the ICU $(26.5 \%)$ or the ward (73.5\%), whereas ICU admission showed significant increase among the non-MS group $(51.4 \%$ vs $26.5 \%$, $p=0.01$ ) (Table 1).

Among MS patients admitted to the ICU, the majority were men $(77.8 \%, p=0.001)$ and a history of smoking was significantly predominant $(88.9 \%$, $p=0.01$ ). The presentation of pneumonia was significantly higher among patients required ICU admission (88.9\%), $p=0.02$. Of MS patients admitted to the ICU, nurses constituted $55.6 \%$, physicians $38.9 \%$, and technicians $5.6 \%$ (Table 2).

Predictors of ICU admission. Using univariate regression analysis, we found that for the MS group, male gender, smoking, and presentation of pneumonia were associated with high risks of ICU admission with COVID-19 infection. The OR [95\% CI] values were as follows: male gender, 9.1 [2.732-30.308], $(p=0.001)$; history of smoking 6.694 [1.453-30.833], $(p=0.01)$; and pneumonia, 5.091 [1.103-23.507], $p=0.03$ (Table 2).

Predictors of death. During follow up, 5 patients out of 483 COVID-19 positive MS patients died. The mortality rate among the MS group was significantly lower than that among the non-MS group (4.6\% vs $13.5 \%, p=0.01)$. Male with a history of chronic kidney disease $(\mathrm{CKD})$ were dominant in the deceased group (7.771 [0.837-72.195], $p=0.07$ for male gender; 10.778 [1.503-77.287], $p=0.02$ for CKD). Table 3 illustrates the predictors of death, with a comprehensive analysis of the main differences between deceased and surviving patients in the MS group.

Discussion. Our study assesses the clinical features and outcomes of COVID-19 infected MS in KSA. We found that the proportion of MS among COVID-19 patients $(23.17 \%)$ was higher than that reported by a meta-analysis of 11 studies, which showed that almost $10 \%$ of positive COVID-19 patients were also healthcare workers. This low ratio reported in the metaanalysis may be due to the timing of the collected data, which occurred early during the pandemic. ${ }^{15}$ Moreover, the data included in this meta-analysis was obtained from only 3 countries: China, the United States, and Italy, although COVID-19 has affected more than 200 countries. ${ }^{16}$ Difference in the ratio may also be related to the degree of workplace exposure for associated MS.

The mean age among infected MS was $44.05 \pm 13.9$ years, which is similar to reports from previous 
COVID-19 infected medical staff ... Abohamr et al

Table 2 - Demographics and clinical characteristics with the risk assessment of ICU admission patients in the medical staff groups.

\begin{tabular}{|c|c|c|c|c|c|}
\hline \multirow[t]{2}{*}{ Demographic data } & \multicolumn{3}{|c|}{ Medical staff group } & \multicolumn{2}{|c|}{ Risk assessment } \\
\hline & Non-ICU $(n=90)$ & ICU $(n=18)$ & $P$-value & OR $(95 \% \mathrm{CI})$ & $P$-value \\
\hline Age (years) Mean $\pm S D$ & $44.02 \pm 14.4$ & $44.2 \pm 11.8$ & 0.8 & $1.012(0.027-1.932)$ & 0.8 \\
\hline \multicolumn{6}{|l|}{ Gender } \\
\hline Female & $65(72.2)$ & $4(22.2)$ & \multirow{2}{*}{$0.001^{\dagger}$} & \multirow{2}{*}{$9.1(2.732-30.308)$} & \multirow{2}{*}{$0.001^{* *}$} \\
\hline Male & $25(27.8)$ & $14(77.8)$ & & & \\
\hline \multicolumn{6}{|l|}{ Nationality } \\
\hline Saudi & $18(20.0)$ & $8(44.4)$ & \multirow{2}{*}{$0.03^{*}$} & \multirow{2}{*}{$3.200(1.105-9.269)$} & \multirow{2}{*}{$0.03^{*}$} \\
\hline Non-Saudi & $72(80.0)$ & $10(55.6)$ & & & \\
\hline \multicolumn{6}{|l|}{ Occupation } \\
\hline Technician & $4 \quad(4.4)$ & $1 \quad(5.6)$ & \multirow{4}{*}{0.8} & $1.245(0.439-3.457)$ & 0.6 \\
\hline Nurse & $53(58.9)$ & $10(55.6)$ & & $1.071(0.103-11.130)$ & 0.9 \\
\hline Pharmacist & $3(3.3)$ & $0 \quad(0.0)$ & & - & - \\
\hline Physician & $30(33.3)$ & $7(38.9)$ & & $0.809(0.279-2.345)$ & 0.7 \\
\hline \multicolumn{6}{|l|}{ History of comorbidities } \\
\hline Smoker & $49(54.4)$ & $16(88.9)$ & $0.01^{*}$ & $6.694(1.453-30.833)$ & $0.01^{*}$ \\
\hline Obesity & $18(20.0)$ & $6(33.3)$ & 0.2 & $2.000(0.66-16.055)$ & 0.2 \\
\hline Hypertension & $15(16.7)$ & $4(22.2)$ & 0.6 & $1.429(0.413-4.945)$ & 0.6 \\
\hline CKD & $5(5.6)$ & $3(16.7)$ & 0.1 & $3.400(0.734-15.749)$ & 0.1 \\
\hline Diabetes mellitus & $31(34.4)$ & $9(50.0)$ & 0.2 & $1.903(0.686-5.284)$ & 0.2 \\
\hline CVA & $2(2.2)$ & $1 \quad(5.6)$ & 0.4 & $2.588(0.222-30.173)$ & 0.4 \\
\hline CVD & $8 \quad(8.9)$ & $1 \quad(5.6)$ & 0.6 & $0.603(0.071-5.142)$ & 0.6 \\
\hline Lung disease & $5(5.6)$ & $3(16.7)$ & 0.1 & $3.400(0.734-15.749)$ & 0.1 \\
\hline \multicolumn{6}{|l|}{ Clinical presentation } \\
\hline Fever & $79(87.8)$ & $17(94.4)$ & 0.4 & $2.367(0.286-19.585)$ & 0.4 \\
\hline Cough & $78(86.7)$ & $17(94.4)$ & 0.4 & $2.615(0.318-21.494)$ & 0.3 \\
\hline Shortness of breath & $76(84.4)$ & $16(88.9)$ & 0.6 & $1.474(0.305-7.131)$ & 0.6 \\
\hline Pneumonia & $55(61.1)$ & $16(88.9)$ & $0.02^{*}$ & $5.091(1.103-23.507)$ & $0.03^{*}$ \\
\hline Heart failure & $0 \quad(0.0)$ & $3(16.7)$ & $0.001^{\dagger}$ & & \\
\hline \multicolumn{6}{|l|}{ Complications } \\
\hline ARDS & $4(4.4)$ & $12(66.7)$ & $0.001^{\dagger}$ & $43.000(10.583-174.710)$ & $0.001^{\dagger}$ \\
\hline Septic shock & $\begin{array}{ll}0 & (0.0)\end{array}$ & $3(16.7)$ & $0.001^{\dagger}$ & & \\
\hline Respiratory failure & $2(2.2)$ & $11(61.1)$ & $0.001^{\dagger}$ & $69.143(12.735-375.415)$ & $0.001^{\dagger}$ \\
\hline Acute kidney injury & $\begin{array}{ll}0 & (0.0)\end{array}$ & $4(22.2)$ & $0.001^{\dagger}$ & & \\
\hline Death & $0 \quad(0.0)$ & $5(27.8)$ & $0.001^{\dagger}$ & & \\
\hline
\end{tabular}

Values are presented as numbers and percentages (\%). CKD: chronic kidney disease, CVA: cerebrovascular accident, CVD: cardiovascular disease, ARDS: acute respiratory distress syndrome, ICU: intensive care unit, OR: odd ratio, CI: confidence interval. $P$-value calculated depend on logistic regression analysis. ${ }^{*} p<0.05$ is significant, ${ }^{\dagger} p<0.01$ is highly significant 
COVID-19 infected medical staff ... Abohamr et al

Table 3 - Demographics and clinical characteristics with the risk assessment of the death patients in the medical staff groups.

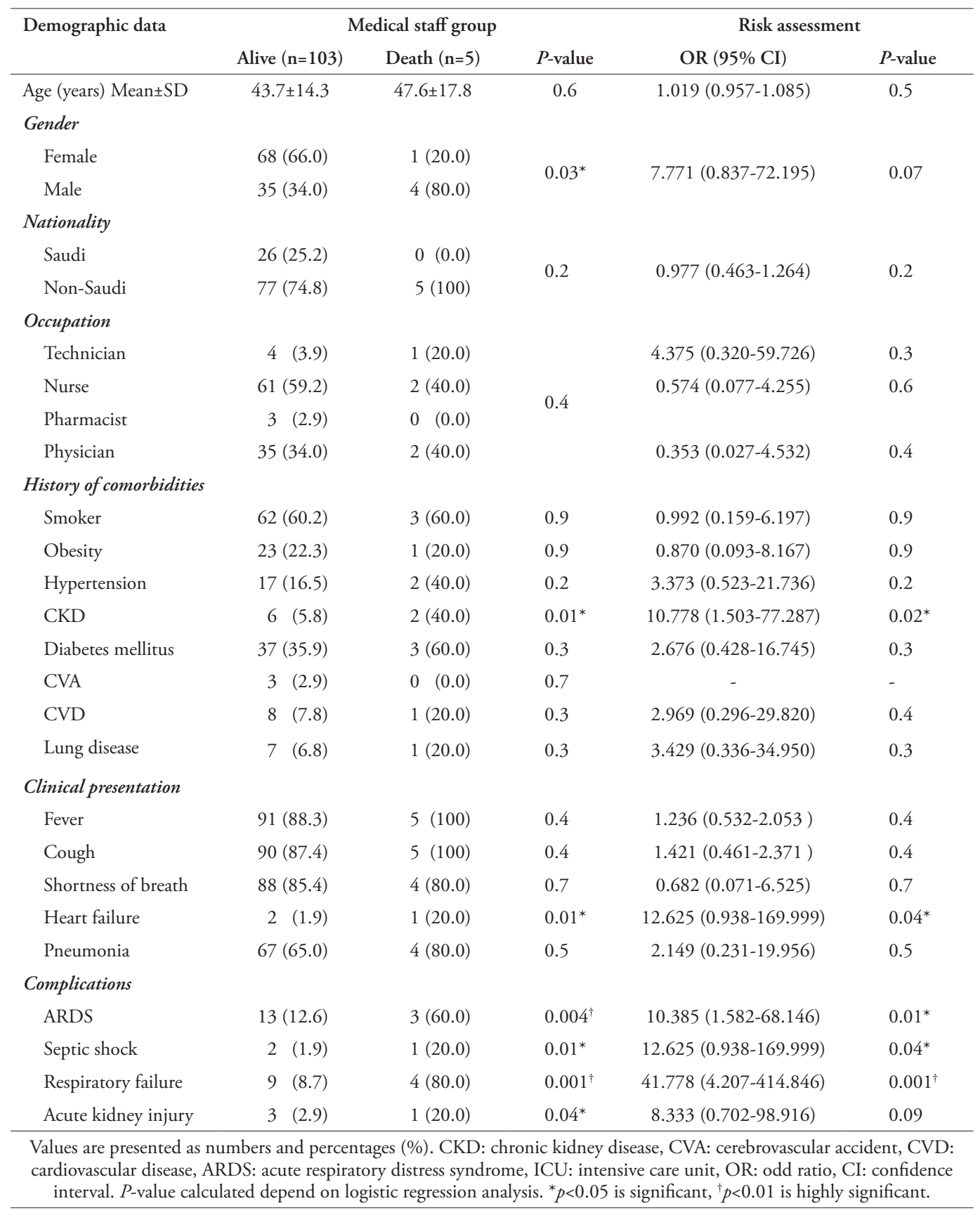

studies. ${ }^{17,18}$ The female gender was predominant among infected MS (63.9\%), and more than half of them $(58.3 \%)$ were nurses, which suggested the differential impacts of various occupations on infection status. This finding also agreed with previous studies that reported that COVID-19-infected MS patients are predominantly female nurses. ${ }^{19,20}$ Nurses appeared more likely to become infected due to longer patientcontact times, followed by physicians and laboratory workers. ${ }^{19,21}$

Importantly, multiple comorbidities can predispose COVID-19 patients to serious infections and various complications. ${ }^{21}$ The most common comorbidities among infected MS patients in our study were diabetes, 
hypertension, obesity, smoking, CKD, and lung disease. This finding is similar to those reported by a previous study examining COVID-19 risk among healthcare workers and the general community. ${ }^{22}$ Fever, cough, and shortness of breath were reported as the most prevalent clinical presentations in both groups, which aligns with other studies on the clinical characteristics of COVID-19-positive MS..$^{20,21}$

Among the MS group in our study, $63.0 \%$ required hospital isolation, compared with $68.8 \%$ of the non-MS group. Further analysis showed that incidence of severity and the necessity of ICU admission among patients in the MS group was 2-fold lower than that among the non-MS group (26.5\% versus [vs] 51.4\%), whereas the fatality rate among the MS group was 3 -fold lower than that among the non-MS group (4.6\% vs $13.5 \%)$. The younger age of healthcare workers and the lower incidence of comorbidities in the MS group relative to the non-MS group may explain these findings. ${ }^{22}$ Healthcare workers may also benefit from the earlier exposure to the healthcare system and a greater understanding of the disease process. ${ }^{15,23}$ Our study also provided comprehensive data regarding predictors of ICU admission and death among severely ill patients in the MS group. Male gender and a history of smoking were found to be fundamental predictors of ICU admission, and male gender and a history of CKD were identified as predictors of death.

A higher rate of respiratory complications among infected MS group patients, including ARDS and RF, compared with the non-MS group, may be explained by the increased risk of exposure to aerosolized viral particles during intubation and the management of COVID-19positive patients. A retrospective study examining 54 COVID-19-positive MS patients revealed that severe and critical cases almost all presented with ARDS and RF. ${ }^{17}$ Moreover, Zhan et al, ${ }^{24}$ reported that 16 out of 23 healthcare workers who died from COVID-19 in their study had ARDS as a complication.

The clinical implications of our study provide insight regarding the vulnerability and clinical presentation of front-line MS with regards to COVID-19 and associated complications in KSA. In addition, both physical and psychological pressure is placed on medical personnel and health workers. ${ }^{25}$ Health workers, as well as the general people, have a high degree of stress due to no firm estimate of how long the global epidemic will last and how long their lives will be affected or whether or not they or their loved ones will be infected. ${ }^{26}$ Our findings determine that additional protective measures may be necessary to reduce infections amongst MS and to identify certain high-risk medical or clinical indicators. Consulting with telemedicine save time and cost and reduce the risk of the spread of infection by avoiding direct contact with COVID-19 patients; thus can play a crucial role in this peculiar time and helps health care providers to be more secure. ${ }^{27}$

Study limitations. This study was performed as a single-center, retrospective study, and the patient sources were not diverse. In addition, the number of MS patients was quite small.

In conclusion, MS are the backbone of successful healthcare systems, as they respond to the emerging COVID-19 pandemic and face new challenges and hazards. The risk of contracting COVID-19 infection among MS is substantial; however, the incidence of death among this population has been significantly low. This finding highlights the significance of proactive steps, including early diagnosis, detection, and isolation, with effective interventions for infection prevention and control, which will benefit not only healthcare providers but also all hospital staff during the COVID 19 pandemic.

Acknowledgment. We would like to thank Cambridge Proofreading LLC for the English language editing.

\section{References}

1. Cucinotta D, Vanelli M. WHO declares COVID-19 a pandemic. Acta Biomed 2020; 91: 157-160.

2. Zhu N, Zhang D, Wang W, Li X, Yang B, Song J, et al. A Novel coronavirus from patients with pneumonia in China, 2019. N Engl J Med 2020; 382: 727-733.

3. Ministry of Health News - MOH Reports First Case of Coronavirus Infection. [Updated 2020. Accessed 2020 August]. Available from URL: https:/www.moh.gov.sa/en/Ministry/ MediaCenter/News/Pages/News-2020-03-02-002.aspx

4. Ministry of Health. Command and Control Center, National Public Health Events, 2020 - Epi-week. [Updated 2020. Accessed 2020 August]. Available from URL: https://www. moh.gov.sa/en/CCC/Pages/default.aspx

5. Perlman S. Another decade, another coronavirus. $N$ Engl J Med 2020; 382: 760-762.

6. Munster VJ, Koopmans M, van Doremalen N, van Riel D, de Wit E. A novel coronavirus emerging in China - key questions for impact assessment. N Engl J Med 2020; 382: 692-694.

7. Chirico F, Nucera G, Magnavita N. COVID-19: protecting healthcare workers is a priority. Infect Control Hosp Epidemiol 2020; 41: 1117.

8. Burrer SL, de Perio MA, Hughes MM, Kuhar DT, Luckhaupt SE, McDaniel CJ, et al. Characteristics of health care personnel with COVID-19 - United States. MMWR Morb Mortal Wkly Rep 2020; 69: 477-481.

9. Wang D, Hu B, Hu C, Zhu F, Liu X, Zhang J, et al. Clinical characteristics of 138 hospitalized patients with 2019 Novel Coronavirus-Infected pneumonia in Wuhan, China. JAMA 2020; 323: 1061-1069. 
10. Guan W, Ni Z, Hu Y, Liang W, Ou C, He J, et al. Clinical characteristics of coronavirus disease 2019 in China. $N$ Engl J Med 2020; 382: 1708-1720.

11. Barello S, Palamenghi L, Graffigna G. Burnout and somatic symptoms among frontline healthcare professionals at the peak of the Italian COVID-19 pandemic. Psychiatry Res 2020; 290: 113129.

12. Qian X, Ren R, Wang Y, Guo Y, Fang J, Wu ZD, et al. Fighting against the common enemy of COVID-19: a practice of building a community with a shared future for mankind. Infect Dis Poverty 2020; 9: 1-6.

13. Ministry of Health, Saudi Center for Disease prevention and Control. Novel Corona Virus (2019-nCoV) Infection Guidelines V1.0. [Updated 2020 January. Accessed 2020 August]. Available from URl: https://www.moh.gov.sa/en/ CCC/healthp/regulations/Documents/Novel\%20Corona\%20 Virus\%20Infection\%20Guidelines.pdf

14. Ministry of Health, Saudi Center for Disease Control and Prevention. COVID-19 Coronavirus Disease Guidelines, v1.3 1. [UPdated 2020 May. Accessed 2020 August]. Available from URL: https://www.moh.gov.sa/Ministry/MediaCenter/ Publications/Documents/Coronavirus-Disease-2019Guidelines-v1.2.pdf

15. Sahu AK, Amrithanand VT, Mathew R, Aggarwal P, Nayer J, Bhoi S. COVID-19 in health care workers - A systematic review and meta-analysis. Am J Emerg Med 2020; 38: 1727-1731.

16. Singh RK, Rani M, Bhagavathula AS, Sah R, Rodriguez-Morales AJ, Kalita H, et al. Prediction of the COVID-19 Pandemic for the Top 15 Affected Countries: Advanced Autoregressive Integrated Moving Average (ARIMA) Model. JMIR Public Health Surveill 2020; 6: e19115.

17. Chu J, Yang N, Wei Y, Yue H, Zhang F, Zhao J, et al. Clinical characteristics of 54 medical staff with COVID-19: A retrospective study in a single center in Wuhan, China. J Med Virol 2020; 92: 807-813.

18. Mani NS, Budak JZ, Lan KF, Bryson-Cahn C, Zelikoff A, Barker GEC, et al. Prevalence of COVID-19 Infection and Outcomes Among Symptomatic Healthcare Workers in Seattle, Washington. Clin Infect Dis 2020: ciaa761.
19. BarrettES, Horton DB, Roy J, Gennaro ML, Brooks A, Tischfield $\mathrm{J}$, et al. Prevalence of SARS-CoV-2 infection in previously undiagnosed health care workers at the onset of the U.S. COVID-19 epidemic. MedRxiv 2020; 2020.04.20.20072470.

20. Rudberg AS, Havervall S, Månberg A, Jernbom Falk A, Aguilera $\mathrm{K}, \mathrm{Ng} \mathrm{H}$, et al. SARS-CoV-2 exposure, symptoms and seroprevalence in healthcare workers in Sweden. Nat Commun. 2020;11: 5064.

21. Richardson S, Hirsch JS, Narasimhan M, Crawford JM, McGinn T, Davidson KW, et al. Presenting characteristics, comorbidities, and outcomes among 5700 patients hospitalized with COVID-19 in the New York City area. JAMA 2020; 323: 2052-2059.

22. Nguyen LH, Drew DA, Graham MS, Joshi AD, Guo CG, $\mathrm{Ma}$ W, et al. Risk of COVID-19 among front-line health-care workers and the general community: a prospective cohort study. Lancet Public Health 2020; 5: e475-e483.

23. McMichael TM, Currie DW, Clark S, Pogosjans S, Kay M, Schwartz NG, et al. Epidemiology of Covid-19 in a long-term care facility in King County, Washington. N Engl J Med 2020; 382: 2005-2011.

24. Zhan M, Qin Y, Xue X, Zhu S. Death from Covid-19 of 23 Health Care Workers in China. N Engl J Med 2020; 382: 2267-2268

25. Montemurro N. The emotional impact of COVID-19: From medical staff to common people. Brain Behav Immun 2020; 87: 23-24.

26. Walton M, Murray E, Christian MD. Mental health care for medical staff and affiliated healthcare workers during the COVID-19 pandemic. Eur Heart J Acute Cardiovasc Care 2020; 9: 241-247.

27. Gadzinski AJ, Gore JL, Ellimoottil C, Odisho AY, Watts KL. Implementing Telemedicine in Response to the COVID-19 Pandemic. J Urol 2020; 204: 14-16. 